\title{
Organic Food purchase motivations, the investigation of the mind-set of an urban Chinese consumer
}

\author{
Anufrieva Ekaterina \\ Shanghai University, Sydney College of Language and Commerce, Shanghai \\ e.anoufrieva@mail.ru
}

\begin{abstract}
Keywords: Organic Food Consumption; Urban Chinese Consumer; Motivation and Purchase
\end{abstract} Intention.

\begin{abstract}
Organic food industry is starting to develop rapidly in China, mainly in big cities such as Shanghai, Beijing, and Guangzhou(Yin et al., 2010).Current study focuses on Organic food consumers in Shanghai and examines factors that have the most impact on intention for purchasing Organic food. Data was collected in Shanghai city through a distribution of hard copy questionnaires. The factors such as internal benefits of consumption, external benefits of consumption, economic cost and the impact of certification and labelling were rated in terms of importance to the consumer while making a purchase decision to buy Organic food.
\end{abstract}

\section{Introduction}

The findings conclude that the most important factor to the Chinese consumer is the internal benefits of consumption, i.e. safety, health and beauty related benefits, superior taste. Another important issue revealed by the study is that the Chinese consumer is very price-sensitive when it comes to purchasing food products including the Organic food range. External benefits of the consumption such as environmental benefits and contribution to the ecological balance, sustainable farming development do not have a strong impact on the Chinese consumer purchase intention. Certification and labeling also did not prove to have a strong impact on the purchase intention. Based on these implications it can be suggested to the Organic food sector companies that their marketing efforts should be focusing mainly on how the consumer benefits from the choice of Organic range products. In addition more information should be provided on how increasing product safety and purity through the lack of usage of pesticides and harmful chemicals makes the Organic farms’ produce more exclusive and limited, which justifies the price premium.

\section{Organic Market Background}

Organic food market is the fastest developing sector in many developed and developing countries. Current literature, examining consumers' awareness of organic food has been well developed in North America and Western Europe (Bonti-Ankomah\&Yiridoe 2006). Organic foods are perceived as being more nutritious, healthier, safer, and environmentally friendly. They contain less chemical residues and taste better than conventional food hence consumers are willing to pay a premium price for organic food (Krystallis et al. 2006).

China has experienced dramatic economic growth over the last twenty years, and is developing an affluent urban middle class for the domestic organic food market. The urban consumer also tends to be more educated and aware of global trends, which includes awareness of the constant growth of Organic food sector in developed countries. Over the recent period the Chinese organic sector has grown faster than the worldwide average. The recent food scandals, health concerns over GMO products in addition to constant exposure to pollution also contribute to the likelihood of further development of strong demand for Organic products in China.

The outlook for the development of the Chinese consumer market for Organic food is great, yet the size of the market remains comparatively small despite the rising incomes and high levels of education among the population in big cities. The level of adoption of Organic food is also quite 
limited compared to developed countries, despite the obvious concerns over food safety among the Chinese consumers. This is however expected to change in the nearest future.

A recent trend emanates from the US, which is called LOHAS - abbreviation for Lifestyle of Health and Sustainability. It refers to a new kind of lifestyle and a trend, which some consumers practice. This trend is already gaining popularity in the affluent cities of China like Shanghai and Beijing (United States Department of Agriculture 2008) A study of Huan Chen in 2014 of product placement of a Lohas juice brand in the context of social games in China demonstrated the customers' sophisticated knowledge of marketing communications and appreciation of consumerist values. The Lohas campaign was considered one of the most successful interactive marketing campaigns in 2009 (Zhan 2009)

In the mature economies Organic food is a known and widely accepted concept, the consumer is aware of the product characteristics and attributes of the organically grown crops as opposed to conventional ones. However in China Organic food is a new concept to the Chinese consumer, which is yet to be comprehended, an innovation that has yet to be adopted by the general public. The product involvement is an issue to be addressed by the marketers and the motivations behind the consumption of Organic products is a key issue to be taken into account. There's a lack of research that investigates which factors precisely are most important in the eyes of the Chinese consumer when it comes to creating incentive to purchase within the Organic range.

Based on previous research the motivations for buying organics include health reasons, environmental concerns, nutritional value, and taste (e.g.. Bourn and Prescott 2002; Fotopoulos and Krystallis 2002; Zanoli and Naspetti 2002) as well as considerations regarding ethics and animal welfare (Makatouni 2002). Some consumers also acknowledge that social approval plays a role in their purchase of organic products (Grunert and Juhl 1995). Self-reported obstacles inhibiting organic product purchase are their low availability and distribution, their price premium, and consumer lack of knowledge (Bonti- Ankomah and Yiridoe 2006). The true motivations however vary in different societies and countries depending on the consumer profile and the domestic market situation. The Chinese consumer mind-set in regards to Organic food is investigated in this study to determine what matters to the urban Chinese consumer most and therefore how the Organic product must be marketed effectively in order to increase purchase intention.Mobilizing Chinese consumer for a sustainable transition to an Organic consumer society should be based on comprehensive knowledge of their motivation, as well as their experienced impediments (Thøgersen et al, 2012).

The study offers useful insight into the motivations behind consumer's intention and purchase behaviour of buying Organic food. Based on the results of the hypotheses tested a number managerial implications can be extracted from the results.Despite the size of the potential consumer market in China, the studies of Organic food and its consumption motivations remain scarce (Chan, 2001; Yin, Wu, Du, \& Chen, 2010). The originality of this study lies in the angle of the research, the focus on consumer and factors that have the most effect on consumer purchase intentions. This study offers a valuable insight for any industry stakeholder including the farmers, the distributors, the retailers, the certification organizations and the government.

\section{Method}

The study is predominantly quantitative in nature. Data was collected through a survey and was carried out in the city of Shanghai where hard copies of questionnaires were distributed to a random sample of 84 people. The results were gathered and analysed via the SPSS software to determine the relationship between the variables. The dimensions in the conceptual model were analysed and hypotheses were tested. The dimensions selected were: Product-related internal benefits, Price related, external benefits to the environment, and certification and labelling. In order to avoid the trap of analysing the purchase intention that may never be realized in practice, the results were tested against the responses that confirmed that they do not only intend to, but purchase Organic food frequently. Chinese respondents were approached in the city centre and asked to contribute to a survey about Organic food. The respondents participated voluntarily and questionnaires were 
anonymous. SPSS was then used to examine data for accuracy, missing values, validity of the model and impact of the factors.

Hypothesis one

H1: Product consumption internal benefits have a positive influence on the purchase intention of the urban Chinese consumer

Hypothesis two

H2: The economic cost of the Organic food product has a negative effect on the purchase intention of the urban Chinese consumer

Hypothesis three

H3: External benefits of Organic food consumption have a positive effect on the urban Chinese consumer purchase intention

Hypothesis four

H4: Trusted Certification and Labeling of Organic food products has a positive effect on the purchase intention of the urban Chinese consumer

\section{Factors and Hypotheses}

[1] Internal Benefits of consumption of Organic food

[2] Economic Cost of consuming Organic food

[3] External Benefits of consumption of Organic food

[4] Certification and Labeling effects on the consumption of Organic food

Internal Benefit can be explained as the benefits the consumer expects to receive from consuming Organic product such as health benefits, weight loss, cleansing of the body, etc. Economic Cost refers to the price the consumer is willing to pay for this pricey choice of a superior product. External Benefits of Organic food consumption includes the environmental benefits, contributing and showing support for the more sustainable agricultural practices. Certification and Labeling stands for trusted certification and labeling. When choosing between conventional and Organic products the consumer's decisions are influenced by the above factors; analyzing the results shows a comparison between these factors and to which extent they influence the decision to purchase Organic food.

A factor analysis was used to cut down the dimensions and avoid multi-collinearity. By selecting the most significant independent variables and quantifying their effect on the purchase intention for Organic food we can make conclusions about what motivates the consumer the most in purchase decisions when it comes to buying organic food in China.

An initial principal components analysis wasconducted. Eigenvalues that are greater than 1 are selected and the number of factors is reduced to four. Variance extracted for all items was more than $50 \%$, meaning that more than half of the variance is explained by the four factors.Based on the four factors in question four hypotheses were created and the validity of the Model was tested through a Regression analysis and the factors were measured in terms of theirsignificance to determine the suitability of the model.

The results suggest the Hypotheses $\mathrm{H} 1$ and $\mathrm{H} 2$ are correct, whereas $\mathrm{H} 3$ and $\mathrm{H} 4$ are rejected. The summary shows that out of the 4 factors analyzed, the significant factors are internal benefits and economic cost. External benefits and certification and labeling have no significant influence on consumers'purchase intention.

Some control variables such aseducation and age are contributing factors behind the purchase intention as well. Interestingly, education is significant at 0.05 level, but the relationship is invert as compared to the positive influence documented in previous literature(Lockie et al., 2002; Storstad and Bjorkhaug, 2003). However Thompson and Kidwell (1998) stated that age, gender, and having a college degree just had little impact on a shopper's decision to buy organic food. Therefore the socio-demographic influence on intention to buy organic food is inconsistent and should be studied in the country-related content. 


\section{Results}

The regression analysis shows how the factors are related to the purchase intention for Organic food. ANOVA F test shows F=2.210, adjusted R Square equals 0.195, which suggests that the four factors have a significant overall predictive power on purchase frequency of organic food.

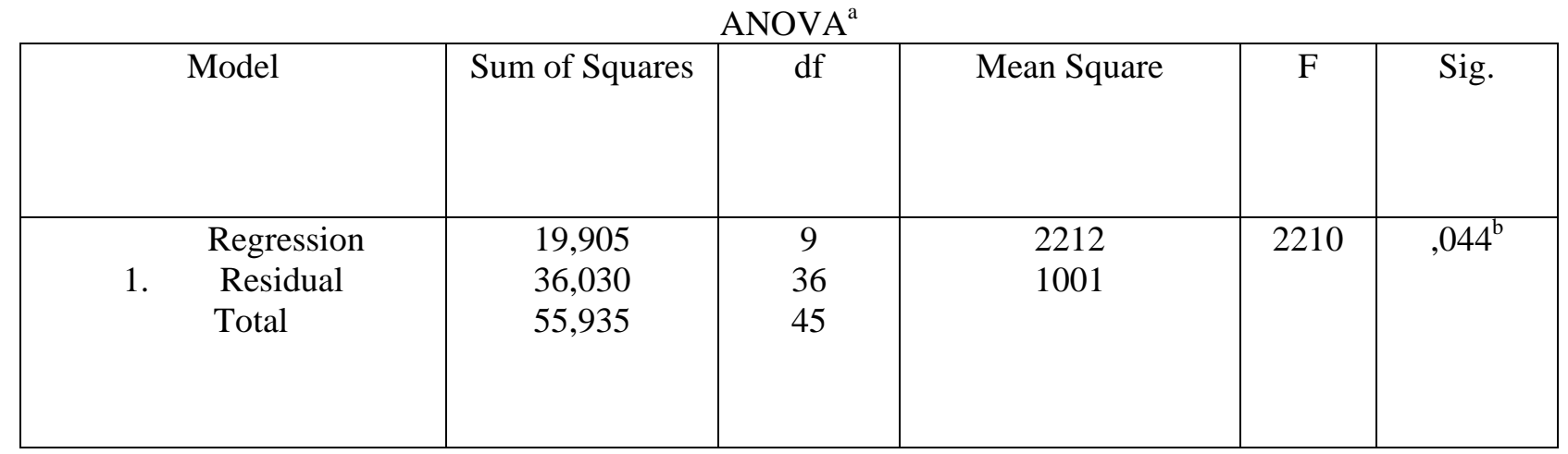

a. Dependent Variable: I buy Organic food frequently

b. Predictors: (Constant), Overseas traveling. Options: 1(tourism), 2(study abroad), 3(business trips), 4(lived abroad), Income. Options: 1(<5000), 2(5000-10,000), 3(10,000-15,000), 4(>20,000), 5(>30,000(), REGR factor score 3 for analysis 1, REGR factor score 2 for analysis 1, REGR factor score 1 for analysis 1, REGR factor score 4 for analysis 1, Gender: 1(female), 2(male), Education. Options: 1 (less than Bsc), 2 (Bsc), 3 (Master), 4 (PHD), 5(Professor), Age.Options:1 (18-25), 2 (25-30), 3 (30-45), 4 (45-60), 5 (other)

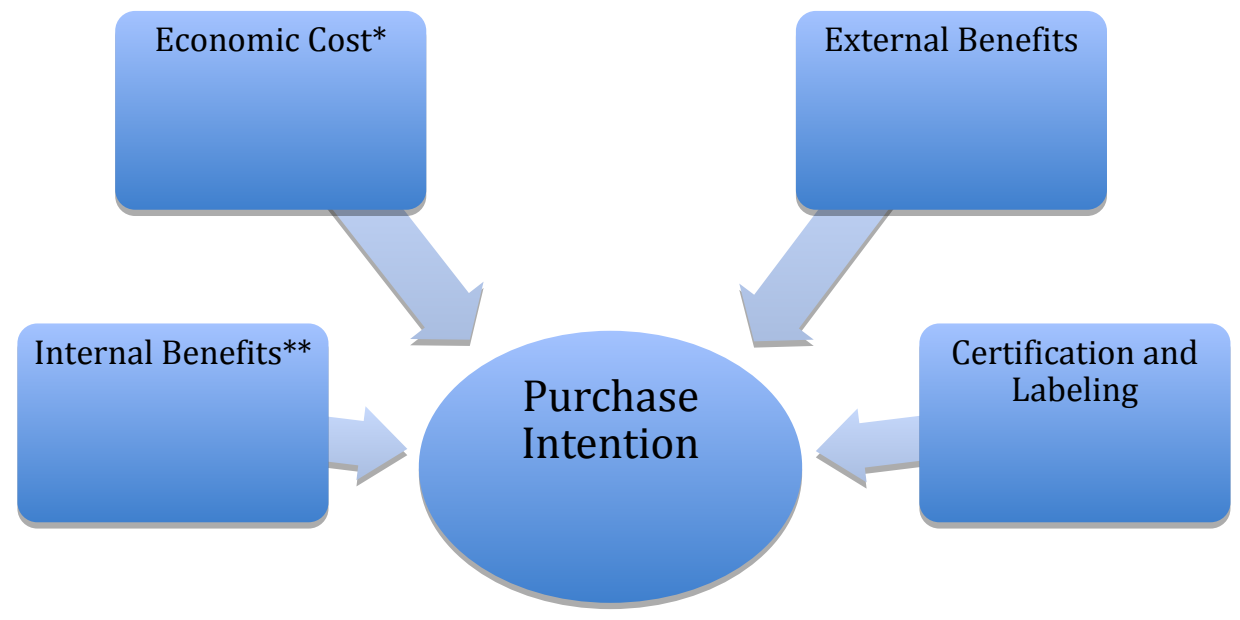

Fig. 1 Factors affecting the purchase intention for Organic food

\section{Conclusion}

The main purpose of this research was to recognize the motivations behind the Chinese consumer's intention to purchase Organic food. As Armstrong and Kotler (2010) state that the intention is the first step to developing demand for Organic food. Mainly the findings should offer angles for marketing the Organic foods in Chinaand should be an important consideration for any Organic food industry stakeholder. The research on Organic food consumption in China as well as the actual trend development still remain limited, which poses many questions as to why this sector is not experiencing fast growth despite the rapid economic, technological and social development. 
Recognizing the obstacles to adoption of the Organic concept is a significant step to eliminating them in the future.

Table 1 Coefficients

\begin{tabular}{|c|c|c|c|c|c|c|c|}
\hline \multirow[t]{2}{*}{ Model } & \multicolumn{2}{|c|}{$\begin{array}{l}\text { Unstandardized } \\
\text { Coefficients }\end{array}$} & \multirow{2}{*}{\begin{tabular}{|l}
$\begin{array}{l}\text { Standardized } \\
\text { Coefficients }\end{array}$ \\
Beta
\end{tabular}} & \multirow[t]{2}{*}{$T$} & \multirow[t]{2}{*}{ Sig. } & \multicolumn{2}{|c|}{ Collinearity Statistics } \\
\hline & B & Std.Error & & & & Tolerance & VIF \\
\hline & 4.005 & .468 & & 8,549 &, 000 & & \\
\hline Internal Benefits & .342 &, 113 &, 354 & 3,014 &, 004 &, 833 & 1,200 \\
\hline Economic Cost &,- 309 &, 108 &,- 312 & $-2,862$ &, 006 &, 967 & 1,035 \\
\hline External Benefits &,- 024 &, 123 &,- 023 &,- 195 &, 846 &, 835 & 1,198 \\
\hline $\begin{array}{l}\text { Certification and } \\
\text { Labeling }\end{array}$ &,- 017 & 108 &,- 017 &,- 154 & ,878 &, 959 & 1,042 \\
\hline Age &,- 069 &, 158 &,- 061 &,- 433 &, 666 &, 571 & 1,750 \\
\hline Education &,- 453 & 179 &,- 297 & $-2,533$ &, 014 & ,838 & 1,193 \\
\hline Income &, 084 &, 115 &, 106 &, 736 &, 464 &, 552 & 1,812 \\
\hline
\end{tabular}

The study is both exploratory and has elements of an inferential nature. The results were analyzed though a multiple regression and are part of an inferential statistical analysis. The results imply that to the Chinese consumer the most important factors is the internal benefits of consumption, therefore they are they ones that should be stressed out when trying to reach the consumer. The Chinese consumer is still at a relatively early stage of accepting the Organic food products and the self-concept is still developing. Therefore more extensive marketing campaigns can help to educate the consumer and to promote the consumption of healthier, safer food options. Health benefits which include cleansing, weight loss, improvement of skin condition and other internal factors which can be discovered through more extensive research that can influence the consumer's decision making process and make them more inclined to purchase within the Organic range.

The study also shows that the Chinese consumer is sensitive to the economic cost of the products. This seems logical at first but at the same time if this sector is to grow in China, it is an important consideration for the parties involved in selling and marketing the organic food range in terms of differentiating their products and communicating the benefits to the consumer and the reasoning for the superior pricing. As opposed to mature marketers in economically developed countries where consumers are relatively less sensitive to the prices due to the consumers' better knowledge of the internal and external benefits of the consumption of the Organic food range, Chinese consumers require more exposure and educational communication in order to be persuaded to pay the premium price for the Organic range.

The external benefits of consumption, which were found to have little impact on the Chinese consumer's purchase intention for Organic food, also provide an insight into the Chinese consumer's mindset. In developed markets one of the motivations for consuming organic food is that it supports environmentally sustainable farming practices and contributes to the ecological balance, it is considered a more ethical and responsible consumer choice. The awareness of the environment and how consumer behavior and choices impact the earth and its well-being in the long run is an attribute the Western consumers have developed over the past decades. However when it comes to the Chinese consumers these concerns do not yet appear to influence the behavior significantly. It can be explained by many reasons such as the activation of consumers' ethical mindset and consumption trends have not yet caught up with the fast economic growth, which has 
occurred in China over the past decade. Major economic and sociological changes are emerging and undoubtedly the 'green innovation' trend adoption will be eminent in the Chinese society in the near future. This logic is consistent with Maslow's theory of the hierarchy of needs, this is apparent in more developed countries but the developing countries are catching up and consumers are becoming increasingly sophisticated and well informed, moreover they now have the disposable income to actually execute more socially responsible shopping choices.

Certification and labeling is another factor that was found to be insignificant to the purchase intention of Organic food. This implies that unlike in developed countries the certification is not working in China in terms of serving the purpose of helping the consumer identify trusted products. This can be partially explained by the food scandals that occurred in China in the past decade, including the faked labeling of unqualified products and charging the consumer a premium for poor quality products. These incidents cause confusion among consumers and lack of trust towards the certification institutes in China. This is a major issue for the organic food sector and it can only be solved by imposing higher standards of food quality control and labeling, increasing the transparency within the food supply chain and traceability of the products to their origin of production. This is an important consideration for managers and certification bodies.

\section{Limitations and Future Research}

Sample size and area covered were limiting factors in this study. Shanghai does not represent the general Chinese consumer due to significant international exposure.

The results may differ significantly in less developed cities, therefore a cross-city study can be carried out to analyze the difference of attitudes among the urban Chinese consumers towards the Organic food in different regions of China. A cross-comparison study of adoption levels and motivations in different cities can be carried out.

The study is non-longitudinal. In order to improve findings results can be collected in stages over a longer time period and perhaps before and after a marketing campaign or a trade show such as Biofach to see how increased awareness and exposure impacts the mindset of the Chinese consumer towards the Organic food.

\section{References}

[1] Aertsens, J., Verbeke, W., Mondelaers, K., Van Huylenbroeck, G. 2009, "Personal Determinants of Organic Food Consumption: a Review”, British Food Journal Emerald Group Publishing Limited, pp. 1140-1167

[2] Ajzen, I \&Fishbein, M 1969, 'The prediction of behaviour intentions in a choice situation ', Journal of experimental social psychology vol. 5, no., pp. 400-416.

[3] Bonti-Ankomah, S \&Yiridoe, EK 2006, Organic and conventional food: a literature review of the economics of consumer perceptions and preference, Nova Scotia Agriculture College, Organic Agriculture Centre of Canada.

[4] Blackwell, RD, Miniard, PW \& Engel, JF 2006, Consumer Behavior 10 edn., Thomson South-Western.

[5] Chan, R.Y.K. (2001). Determinants of Chinese consumers' green purchase behavior.Psychology and Marketing, 18, 389-413

[6] Chen, H., Haley, E. 2014, "Product Placement in Social Games: Consumer Experiences in China”, The Journal of Advertising, pp. 286-295

[7]Deng, X. 2013, “Factors Influencing Ethical Purchase Intentions Of Consumers In China”, Ethical Purchase Intentions, pp. 1693-1704 
[8 ]Frostling-Henningsson, M., Hedbom, M., Wilandh, L. 2014, “Intentions to Buy "Organic” Not Manifested in Practice”, British Food Journal Emerald Group Publishing Limited, pp. 872-887

[9 ]Honkanen, P, Verplanken, B \& Olsen, SO 2006, 'Ethical values and motives driving organic food choice', Journal of Consumer Behaviour, vol. 5, no. 5, pp. 420-430.

[10] Krystallis, A., Chryssohoidis, G. 2005, “Consumers’ Willingness to Pay for Organic Food. Factors That Affect It and Variation per Organic Product Type”, British Food Journal Emerald Group Publishing Limited, pp. 320-343

[11] Marian, L., Thogersen, J. 2013, "Direct and Mediated Impacts of Product and Process Characteristics on Consumers' Choice of Organic vs. Conventional Chicken”, Food Quality and Preference, pp. 106-112

[12] Paul, J., Rana, J. 2012, “Consumer Behavior and Purchase Intention for Organic Food”, Journal of Consumer Marketing Emerald Group Publishing Limited, pp. 412-422

[13]Perrea, T., Grunert, K. G, Krystallis, A., Zhou, Y., Huang G., Hue, Y. 2014, "Testing and Validation of a Hierarchical Values-Attitudes Model in the Context of Green Food in China”, Asia Pacific Journal of Marketing and Logistics, pp. 296-314

[14] Portocarrero, 2011 'Organic Food Products in China: Market Overview', International Trade Centrereport, Geneva: ITC, 2011. xii, 36 pages (Technical paper) Doc. No. SC-11-196.E

[15] Sirieix, L., Kledal, P. R., Sulitang, T. 2011, “Organic Food Consumers’ Trade-offs between Local or Imported, Conventional or Organic Products: a Qualitative Study in Shanghai”, International Journal of Consumer Studies, 670-678

[16] Thogersen, J., Zhou, Y. 2012, “Chinese Consumers’ Adoption of a ‘Green’ Innovation - The Case of Organic Food”, Journal of Marketing Management, pp. 313-333

[17] Xin-an, Z., Grigoriou, N., Ly, L. 2008, “The myth of China as a Single Market. The Influence of Personal Value Differences on Buying Decisions”, International Journal of Market Research, pp. 377-397

[18] Yin, S., Wu, L., Du, L., \& Chen, M. (2010). Consumers’ purchase intention of organic food inChina. Journal of the Science of Food and Agriculture, 90, 1361-1367

[19] Zhou, Y., Thøgersen, J., Ruan, Y., Huang, G. 2013, “The Moderating Role of Human Values in Planned Behavior: The Case of Chinese Consumers' Intention to Buy Organic Food”, Journal of Consumer Marketing Emerald Group Publishing Limited, pp. 335-345 